\title{
ASO Author Reflections: Stage-Adjusted Reduced Follow-Up of Melanoma Patients is Justified and Cost Effective, Until Biomarkers to Predict Prognosis Have Been Identified
}

\author{
Anne Brecht Francken, MD, PhD ${ }^{1}$, Josette E. H. M. Hoekstra-Weebers, PhD $^{2}$, Eric Deckers, $\mathbf{M D}^{3}$, and \\ Harald J. Hoekstra, MD, PhD $^{3}$ \\ ${ }^{1}$ Department of Surgical Oncology, Isala Clinics, Zwolle, The Netherlands; ${ }^{2}$ Wenckebach Institute, University of \\ Groningen, University Medical Center Groningen, Groningen, The Netherlands; ${ }^{3}$ Department of Surgical Oncology, \\ University of Groningen, University Medical Center Groningen, Groningen, The Netherlands
}

\section{PAST}

The incredible rise in melanoma health care costs urgently demands a reduction in these costs where appropriate. ${ }^{1}$ Nevertheless, cancer patients demand frequent and close follow-up out of fear of recurrence. Historically, melanoma patients have been followed regularly, with limited therapeutic options in case of disease progression. ${ }^{2}$ In addition, survival benefit as a result of follow-up has never been demonstrated. ${ }^{3}$ There is a lack of international consensus regarding the follow-up frequency of melanoma patients, ${ }^{4}$ and evidence regarding the optimal follow-up frequency of these patients with respect to disease-free and overall survival, patients' quality of life (QoL), and costs is highly needed.

ASO Author Reflections is a brief invited commentary on the article "The MELFO-Study: a Multi-Center Prospective Randomized Clinical Trial on the Effects of a Reduced Stage-Adjusted Follow-up Schedule on Cutaneous Melanoma IB-IIC patients: Results After 3-Years", Ann Surg Oncol. In press

(C) The Author(s) 2019

First Received: 19 June 2019; Published Online: 3 September 2019

H. J. Hoekstra, MD, PhD

e-mail: h.j.hoekstra@umcg.nl

\section{PRESENT}

The current randomized controlled MELFO study compared two groups of stage Ib-IIc melanoma patients, 3 years after diagnosis. ${ }^{5}$ The first group received follow-up as advised in the guideline, while the second group received a stage-adjusted, less frequent follow-up schedule. Patients' QoL, anxiety, satisfaction regarding follow-up, and disease-free and overall survival were comparable, but a $39 \%$ cost reduction was found in those who were less frequently followed-up. A reduced and stage-adjusted follow-up schedule could be a step forward in better distribution of resources, such as finances, time, and manpower.

\section{FUTURE}

Several questions need to be answered in the future to determine the optimal, safe, (cost)-effective follow-up that will benefit all melanoma patients. ${ }^{3}$ Apart from recurrence detection, mental support and patient education are important after-care goals for melanoma patients with any stage of disease. ${ }^{6,7}$ Now that several effective therapeutic adjuvant systemic treatment options with drug targeting and/or immunotherapy have become available, follow-up has become even more complex. ${ }^{8}$ What is the best strategy to improve OS in stage IB-II melanoma? Adjuvant therapy of high-risk stage II patients or treatment at the time of recurrence? How to select patients who will benefit from adjuvant treatment while sparing those who are unlikely to benefit from toxic effects? If melanoma biomarkers could be identified that can better predict the potential to metastasize than the current prognostic factors do, a 
personalized follow-up, including emotional support and patient education, could be delivered even more (cost) effectively. Currently, stage-adjusted follow-up is the best personalized follow-up approach for stage IB-II melanoma.

DISCLOSURES Anne Brecht Francken, Josette E.H.M. HoekstraWeebers, Eric Deckers, and Harald J. Hoekstra have no conflicts of interest to disclose.

OPEN ACCESS This article is distributed under the terms of the Creative Commons Attribution 4.0 International License (http://crea tivecommons.org/licenses/by/4.0/), which permits unrestricted use, distribution, and reproduction in any medium, provided you give appropriate credit to the original author(s) and the source, provide a link to the Creative Commons license, and indicate if changes were made.

\section{REFERENCES}

1. Guy GP Jr, Ekwueme DU, Tangka FK, Richardson LC. Melanoma treatment costs: a systematic review of the literature, 1990-2011. Am J Prev Med. 2012;43:537-45.
2. Francken AB, Bastiaannet E, Hoekstra HJ. Follow-up in patients with localised primary cutaneous melanoma. Lancet Oncol. 2005;6:608-21.

3. Fields RC, Coit DG. Evidence-based follow-up for the patient with melanoma. Surg Oncol Clin North Am. 2011;20:181-200.

4. Cromwell KD, Ross MI, Xing Y, Gershenwald JE, Royal RE, Lucci A, et al. Variability in melanoma post-treatment surveillance practices by country and physician specialty: a systematic review. Melanoma Res. 2012;22:376-85.

5. Deckers EA, Hoekstra-Weebers JEHM, Damude S, Francken AB, ter Meulen S, Bastiaannet E, et al. The MELFO-study: a multicenter prospective randomized clinical trial on the effects of a reduced stage-adjusted follow-up schedule on cutaneous melanoma IB-IIC patients: results after 3-years. Ann Surg Oncol. (in press).

6. Morton RL Rychetnik L, Mccaffery K, Thompson JF, Irwig L. Patients' perspectives of long-term follow-up for localised cutaneous melanoma. Eur J Surg Oncol. 2013;39:297-303.

7. Lim WY, Morton RL, Turner RM, Jenkins MC, Guitera P, Irwig L, et al. Patient preferences for follow-up after recent excision of a localized melanoma. JAMA Dermatol. 2018;154:420-7.

8. Schadendorf D, van Akkooi ACJ, Berking C, Griewank KG, Gutzmer R, Hauschild A, et al. Melanoma Lancet. 2018;392:971-84.

Publisher's Note Springer Nature remains neutral with regard to jurisdictional claims in published maps and institutional affiliations. 